M. Gerbaldi: We are very careful to ask participants about their backgrounds, and structure activities accordingly. The participants were very satisfied.

C. Iwaniszewska: I would like to comment about the publication of the big volume after the Summer University; it is a lot of extra work for the organizers, but is so very useful for participants.

M. Gerbaldi: This year, in 1988, we reproduced the text of all the lectures before the beginning of the Summer University in order to give them immediately to the participants. For the results of the small workshops and the practical classes, small groups of participants wrote down, in a few pages, the results they obtained and how the scale models or the small instruments were made. We rented a photocopy machine to reproduce all these reports and they were distributed to all the participants. Thus this year, every participant went home with the proceedings.

\title{
THE UNIVERSE IN THE CLASSROOM: A NEWSLETTER ON ASTRONOMY FOR TEACHERS
}

\section{Andrew Fraknoi}

Astronomical Society of the Pacific, 390 Ashton Ave, San Francisco, California 94112 , U.S.A.

Since 1984, the Astronomical Society of the Pacific (ASP) has sponsored a quarterly newsletter on teaching astronomy in grades 3-12. Cosponsored by the American Astronomical Society, the Canadian Astronomical Society, and the International Planetarium Society, the project now reaches over 20,000 teachers and schools in the US and Canada.

We would like colleagues overseas to examine the newsletter, and, if they find it useful, to consider translating and distributing it. We will be glad to make it available without charge to anyone who is interested.

\section{The History of the Newsletter}

Since 1978, the summer meetings of the ASP - held in a different city each year - have featured one to three days set aside for workshops on astronomy for teachers. In recent years, between 150 and 200 teachers have come each summer - at their own expense - to take these credit workshops and learn more about astronomical topics, activities, and resources.

Participants in these workshops asked the ASP year after year if we could set up a way for the "graduates" to keep in touch with us and continue to get updates, especially about new discoveries and new teaching resources. In late 1984, with a 
grant from the US National Academy of Science's Slipher Fund, we were finally able to respond to their requests by starting a newsletter on teaching astronomy.

We set up a distinguished Board of Advisers for the newsletter, consisting of noted astronomers and educators in the US and Canada, and sent a news release to our workshop "graduates" and some teachers' and astronomy journals. We thought that in its first year, announcements of the newsletter would probably generate several hundred requests, mainly from alumni of our workshops and other astronomy workshops around the country. We were shocked to receive about 10,000 requests for Universe in the Classroom during the 12 months after the project was announced.

These requests came from schools and teachers throughout the US and Canada. and from grade levels ranging from first grade through community college. A significant number of requests were received from professors of science education in universities with a special interest in teaching teachers.

We had already asked the American Astronomical Society to cosponsor the project and their Council gave it an enthusiastic endorsement and its financial assistance. We then began to look around for other sources of support and assistance. Starting at home, the ASP Board decided to devote most of the interest from the new Bart J. Bok Memorial Endowment to help the newsletter. The Canadian Astronomical Society stepped in to help support the mailing of issues to Canada. Associated Universities, Inc., and the National Radio Astronomy Observatory gave us some welcome support. And the Slipher Fund has generously continued its financial assistance to the project for several years. A number of other foundations and companies have also helped with printing, equipment, and other forms of assistance.

\section{The Newsletter Today}

The newsletter is offered free of charge to teachers, librarians, and youthoriented-group leaders. Only written requests for the newsletter are honored and subscribers are asked to write in on school or youth-group stationery, to make sure that we are not sending copies to students or the public.

The issues so far have been written by Andrew Fraknoi and Sherwood Harrington (ASP) with contributions by Dennis Schatz (of the Pacific Science Center) and John Percy (of the University of Toronto). Each issue features astronomy information, one or more classroom or observing activities, and a section on teaching resources.

We write each issue of the newsletter with a varied audience in mind. We want to please not only the experienced science teacher but also the beginner with very little science background who may be facing his or her first-grade class. Many of these teachers have told us they don't cover topics in modern astronomy because they are afraid their students will know more than they do. The newsletter tries to address such concerns by giving them information and tools that they can put to immediate use in the classroom, as well as resources for further information for both students and teachers. 


\section{The Universe in the Classroom}

\section{A Newsletter on Teaching Astronomy}

Sponsored by the:

Aotronomical Society of the Pacific

American Aatronomical Society

Canadian Astronomical Soctety

International Planetarium Society

Number 12 copyright 1989, Astronomical Society of the Pacific
390 Ashton Ave., San Francisco, CA 94112

\section{Activity Corner}

\section{How Soon Can You See a Crescent Moon?}

An interesting activity is to see what the youngest crescent Moon is that you can see. Some very experienced observers are able to see the Moon less than 24 hours after it's new. How well can you do?

IFor an article on an intemational effort to see a very young crescent, see: "Moonwatch - July 14, 1988" by $L$. Doggett, et al., in Sky \& Telescope, July 1988, p. 34.]

\section{When is the Moon Visible?}

It is often surprising to youngsters that the Moon sometimes can be seen in the daytime sky. Just when the Moon rises and sets depends primarily on its phase, and only at full Moon does it behave as some might expect - that is, to rise at around sunset and be up all night long.

Keeping track of the visibility of the Moon as it cycles through its phases can be a fascinating (and instructive) thing to do. Moontracking activities could follow a wealth

of different paths - from precise timing of moonrise and moonset to a more general noting of where the Moon is (and what phase it's in) each time you see it.

To help you devise a program of Moon-viewing, the accompanying table charts the times when the Moon rises, sets, and so on during its different phases. We shoukd note that the times in the table are very general (correct to within an hour or $(w o)$. The precise times of moonrise, moonset, and so on depends on a number of factors besides the Moon's phase - your location on Earth (latitude and longitude) has a major effect, for example. (Exact local times of moonrise and moonset are often printed in large daily newspapers, usually in the weather section.)

Notice that knowing when the Moon rises and sets in its various phases allows you to tell time (roughly) whenever it is visible! For example, if you're awakened in the night on a camping trip and you notice a third quarter moon high in the eastern sky, then you know that sunrise is coming soon On the other hand, a full moon high in the sky would reassure you that you have plenty of time for more sleep the full moon is highest around midnight.

\section{Lunar Eclipses}

Observing a lunar eclipse (which - because it can be seen over a much wider area is much more eas ily seen than a solar eclipse) is a safe and enjoyable fam. ily activity. Upcom. ing eclipses are listed in astronomy magazines such as Sky \& Telescope and Astronomy, as well as in the Abrams Planetarium Sky Calendar that comes with membership in the Astronomical Society of the Pacific. No special precautions need to be taken in viewing such an eclipse, and it's fun to organize family, friends, and neighbors when you know such an eclipse is coming.

A typical item from a typical issue of The Universe in the Classroom.

This year, the International Planetarium Society has joined the Societies in- 
volved with the newsletter as a sponsor. Because planetariums represent the largest and most effective interface between professional astronomy and teachers, we are especially pleased to have them as partners in this endeavor and are working with them to encourage even wider redistribution of each issue through local planetariums.

\title{
3. Looking to the Future
}

At present the direct circulation of the newsletter is over 20,000 and still climbing. In many schools and school districts, the initial recipients make dozens or hundreds of additional copies for further distribution. In addition, articles from our newsletter have been excerpted and reprinted in many dozens of local and national magazines and newsletters read by teachers.

We would like to encourage our colleagues from around the world to translate and distribute the newsletter in their own countries, if it is appropriate. To obtain some recent issues and more information, please write the author at:

\author{
Teachers' Newsletter Distribution \\ Astronomical Society of the Pacific, \\ 390 Ashton Ave., \\ San Francisco, California 94112, U.S.A.
}

Whether or not you wish to (or need to) translate, please feel free to duplicate copies to teachers and others who can use them. (Each issue contains a paragraph giving educational institutions blanket permission to make additional copies). The only thing we ask is that you either reproduce the issue in full or - if you only use specific articles - that you give full credit and copyright information on each copy.

\section{A SCIENCE AND MATHEMATICS TEACHING CENTER}

\author{
Walter Bisard
}

Central Michigan University, Mt. Pleasant, Michigan 48859, U.S.A.

\section{A Crisis in Science Education?}

It is widely known that a crisis in science and mathematics teaching exists in the United States. This crisis has reached all levels of education, from elementary to secondary to colleges and universities. The problem, which is easy to define but difficult to resolve, is trifold: there are not enough high-quality science and mathematics teachers; present teachers are teaching out-of field or are out-of-date and in need of subject updating; and the average education graduate is only minimally 